\title{
Symbiogenetics underway: from genetic analysis to genetic synthesis
}

Symbiogenetics is a completely new research field aimed at studying the variability and heredity in superorganismal systems composed by distant species during intimate symbiotic interactions. The emergence and swift progress of this field are based on the genetic analysis of inter-species interactions, which play a crucial role in the development, adaptation and evolution of nearly all living creatures. However, we do not consider symbiogenetics as a paraphrasing for "genetics of symbiosis": it is a fundamental area of biology which represents a holistic approach to studying the genomic integration of distant species. This approach, aimed at analyzing superorganismal genetic systems (Tikhonovich and Provorov, 2009), complements the traditional reductionist methodology of genetic analysis based on the dissection of hereditary material into the elementary units - genes, cistrons, mutons, recons, codons, etc. (Benzer, 1957; Lobashev, 1967; Inge-Vechtomov, 1983).

Historically, symbiogenetics emerged at the border of ecological genetics, which addresses the impacts of environmental factors on genetic processes (IngeVechtomov, 2015), and the symbiogenesis theory, which proposes that eukaryotic cells originated via integration of distant prokaryotic forms (Mereschkowsky, 1910; Margulis, 1996; Provorov et al., 2018). This is why symbiogenetics considers the tight integration of diverse species as their fundamental adaptive strategy based on the immanent properties of genetic material expressed at all levels of its organization. The universal mechanisms for maintenance, transmission and expression of hereditary information provide opportunities for merging the genomes of distant organisms (prokaryotes and eukaryotes, bacteria and archaea), which results in functionally and structurally integrated systems.

Previously we suggested that in symbiotic systems, the elementary units of heredity are represented not by individual genes (as in free-living organisms subjected to conventional genetic analysis) but by extra-gene systems, at least by pairs of genes belonging to the interacting partners (Tikhonovich and Provorov,

Citation: Provorov, N. and Tikhonovich, I. 2021. Symbiogenetics underway: from genetic analysis to genetic synthesis. Bio. Comm. 66(1): 3-5. https://doi. org/10.21638/spbu03.2021.101

Authors' information: Nikolay Provorov, Dr. of Sci. in Biology, Professor, Director of ARRIAM, orcid.org/0000-0001-9091-9384 Igor Tikhonovich, RAS Academician, Dr. of Sci. in Biology, Professor, Director for Science of ARRIAM, Dean of Faculty, orcid. org/0000-0001-8968-854X

Manuscript Editor: Pavel Skutschas,

Department of Vertebrate Zoology, Faculty of Biology, Saint Petersburg State University, Saint Petersburg, Russia

Received: May 17, 2020

Revised: July 15, 2020;

Accepted: August 10, 2020.

Copyright: @ 2021 Provorov and Tikhonovich. This is an open-access article distributed under the terms of the License Agreement with Saint Petersburg State University, which permits to the authors unrestricted distribution, and self-archiving free of charge.

Funding: Supported by the Russian Science Foundation, Grants 19-16-00081 (genomic integration) and 17-76-30016 (signaling interactions).

Competing interests: The authors have declared that no competing interests exist. 2012). Developing an approach coined by W. Q. Loegering (1978), who suggested for symbiosis a specific phenotype represented by the "emergent traits" (von Bertalanffy, 1968), we proposed for symbiosis a distinct genotype based on the integration of partners' genomes. Preliminarily, it may be addressed in terms of the partners' genomic complementation (Tikhonovich et al., 2015), although the resulting integrative evolution should not be restricted to the genome interaction: in the course of partners' co-adaptation, communalized systems for variability and heredity are emerging.

To address these composite genomes, the notion of "hologenome" has been introduced, which denotes an integral genetic system composed of all genes harbored by the eukaryotic host and its associated microbial community (ZilberRosenberg and Rosenberg, 2008). However, this definition cannot be considered universal since symbiotic interactions implemented in the communities formed by plants or animals with their microbial cohabitants are extremely diverse: they range from sporadically emerging, transient associations to strictly obligatory, vertically transmitted ones. This is why we consider a "symbiogenome" as a major product of facultative symbiosis in which the specialized partners' genes are involved. In a historical perspective, the provisionally emerged symbiogenomes tend to be reorganized into obligatory hologenomes in which the permanent coexistence of diverse organisms assumes the participation of the whole partners' genomes in a cooperative interaction. 
In the model $\mathrm{N}_{2}$-fixing legumerhizobia association, the symbiogenome involves the partners' genes used in signal interactions (e.g., bacterial nod genes for the synthesis of lipo-chito-oligosaccharidic Nod factors + plant NFR genes for their reception) and in the metabolic exchange (e.g., bacterial nif/fix genes for nitrogenase synthesis/operation + plant GS/GTS/AAT genes for assimilating the nitrogenase reaction products). For these genes, coevolution was demonstrated at the population and phylogenetic levels (Andronov et al., 2015; Shatskaya et al., 2019), which resulted in a marked increase of symbiogenome complexity and integrity.

Analysis of the diverse microbe-plant interactions, including legume-rhizobia symbiosis, arbuscular mycorrhizae and the endophytic/epiphytic associations, demonstrate that at least some genes used by plants for cross-talking with microbial cohabitants are universal (Tikhonovich et al., 2015). It seems that from the very beginning of their natural history, land plants acquired a system for hosting and managing the beneficial symbionts which were diversified broadly to meet the phylogenetic and ecological radiation of microbial partners. During adaptation to various environments, plants gained a range of mechanisms for recruiting the beneficial symbionts from external sources (e.g., from soils) and from the associated (e.g., endophytic) communities providing to their hosts the urgent nutritional, defensive and regulatory functions.

In this special issue of Biological Communications, we are going to illustrate the major ideas of symbiogenetics using the models of tightly integrated microbe-plant and microbe-animal symbioses in which the micropartners colonize the internal niches of host organisms. Given that many beneficial symbioses are closely related to parasitic interactions (de Bary, 1879; Provorov, 2019), we will address several examples of host-pathogen systems which allow us to dissect the evolutionary continuum of mutualistic and antagonistic communications. Importantly, in some pathosystems, partners' interactions are very tight, as illustrated by the microbe $\rightarrow$ host transfer of effector proteins mainly via different secretion systems, or even of symbiotically essential genes (e.g., in Agrobacterium responsible for plant onco-transformation), suggesting excellent models for cooperative adaptation and integrative evolution covering different levels of genomic organization.

Finally, we are going to demonstrate that the integrative approaches provided by symbiogenetics have a pronounced applied potential aimed at constructing the superspecific systems for agricultural, biomedical and environmental purposes.

\section{Acknowledgements}

Since the major ideas of symbiogenetics have originated as a summary of genetic research on plant-microbe symbioses implemented in the All-Russia Research Institute for Agricultural Microbiology during the last 40 years of its 90-year history, the authors are cordially grateful to all colleagues who contributed to this exciting development.

Nikolay Provorov and Igor Tikhonovich, Guest Editors of this Special Issue of "Biological Communications"

\section{References}

Andronov, E. E., Igolkina, A. A., Kimeklis, A. K., Vorobyov, N. I., and Provorov, N. A. 2015. Characteristics of natural selection in populations of nodule bacteria (Rhizobium leguminosarum) interacting with different host plants. Russian Journal of Genetics 51(10):949-956. https://doi.org/10.1134/S1022795415100026

Benzer, S. 1957. The elementary units of heredity. In McElroy, W. D., Glass B. (eds.). The chemical basis of heredity. Baltimore, Maryland: Johns Hopkins Press, pp. 70-93.

de Bary, A. 1879. Die erscheinung der symbiose. Strassburg: Verlag Von K. J. Trübner. https://doi.org/10.1515/9783111471839 Inge-Vechtomov, S. G. 1983. Introduction into molecular genetics. Moscow, Russia: Higher School.

Inge-Vechtomov, S. G. 2015. Genetics in retrospect. St.-Petersburg, Russia: N.-L. Publ. (In Russian)

Lobashev, M. E. 1967. Genetics. Leningrad, Russia: Leningrad Univ. Publ. (In Russian)

Loegering, W. Q. 1978. Current concepts of inter-organismal genetics. Annual Review of Phytopathology 16:309-320. https://doi. org/10.1146/annurev.py.16.090178.001521

Margulis, L. 1996. Archaeal-eubacterial mergers in the origin of Eukarya: phylogenetic classification of life. Proceedings of the National Academy of Sciences USA 93(3):1071-1076. https://doi.org/10.1073/pnas.93.3.1071

Mereschkowsky, C. 1910. Theorie der zwei Plasmaarten als Grundlage der Symbiogenesis, einer neuen Lehre von der Entstehung der Organismen. Biologisches Centralblatt 30:278-288.

Provorov, N. A. 2019. Trade-off between mutualism and antagonism in the microbe-plant interactions: the concept of pleiotropic symbiosis. Mycologia i fitopatologia 53(2):67-79. https://doi.org/10.1134/S0026364819020089 (In Russian)

Provorov, N. A., Tikhonovich, I. A., and Vorobyov, N. I. 2018. Symbiosis and symbiogenesis. St.-Petersburg, Russia: Inform-Navigator. (In Russian) 
Shatskaya, N. V., Bogdanova, V. S., Kosterin, O. E., Vasiliev, G. V., Kimeklis, A. K., Andronov, E. E., and Provorov, N. A. 2019. Plastid and mitochondrial genomes of Vavilovia formosa (Stev.) Fed. and phylogeny of related legume genera. Vavilov Journal of Genetics and Breeding 23(8):972-980. https://doi.org/10.18699/VJ19.574

Tikhonovich, I. A. and Provorov, N. A. 2009. From plant-microbe interactions to Symbiogenetics: a universal paradigm for the inter-species genetic integration. Annals of Applied Biology 154(3):341-350. https://doi.org/10.1111/j.1744-7348.2008.00306.x

Tikhonovich, I. A. and Provorov, N. A. 2012. Development of symbiogenetic approaches for studying variation and heredity of superspecies systems. Russian Journal of Genetics 48(4):357-368. https://doi.org/10.1134/S1022795412040126

Tikhonovich, I. A., Andronov, E. E., Borisov, A. Yu., Dolgikh, E. A., Zhernakov, A. I., Provorov, N. A., Rumyantseva, M. L., and Simarov, B. V. 2015. The principle of genome complementarity in the enhancement of plant adaptive capacities. Russian Journal of Genetics 51(9):831-846. https://doi.org/10.1134/S1022795415090124

von Bertalanffy, L. 1968. General system theory: foundations, development, applications. N. Y.: George Braziller.

Zilber-Rosenberg, I. and Rosenberg, E. 2008. Role of microorganisms in the evolution of animals and plants: the hologenome theory of evolution. FEMS Microbiology Reviews 32(3):723-735. https://doi.org/10.1111/j.1574-6976.2008.00123.x 